\title{
With Feeling: How Emotions Shape Negotiation
}

\author{
Mara Olekalns \\ Melbourne Business School, University of Melbourne, Australia (e-mail: m.olekalns@mbs.edu)
}

Daniel Druckman

George Mason University, Fairfax, VA 22030 (e-mail: ddruckma@gmu.edu)

Macquarie University, Sydney, Australia

Olekalns, M., \& Druckman, D. (2014). With Feeling: How Emotions Shape Negotiation (State-of-the-Art Commentary), Negotiation Journal, 30, 455-478. 
An increasingly popular topic in current research is how emotional expressions influence the course of negotiation and related interactions. Negotiation is a form of social exchange that pits the opposing motives of cooperating and competing against one another. Most negotiators seek to reach an agreement with the other party; they also strive for an agreement that serves their own goals. This dual concern is reflected in a process that consists of both bargaining and problem solving. A good deal of the research and practice literature concentrates on ways to perform these activities effectively. In earlier writing, emotions were viewed largely as factors that impede performance, preventing successful coordination from occurring. More recently we have learned that emotions can both help and hinder progress. Expressions may convey useful information about preferences; they can also signal dislike or malevolent intentions. Whether emotions move a negotiation forward or backward -- or improve/threaten a relationship -depends on a variety of process and context variables. We explore these variables in more depth in this chapter.

The study of emotions has been neglected in a literature that emphasizes strategy and information processing. This emphasis is prominent in several dominant paradigms that have guided much of the research, including game and decision theory, behavioral approaches, cognitive framing/prospect theory, and the dual concern model. Concepts such as motives, trust and identity that seem to have substantial emotional content have been described mostly in terms of strategy. Motives have been construed in terms of relative and absolute or joint gains (De Dreu, Weingart and Kwon, 2000; Hopmann, 1995). Trust has been defined as calculus, knowledge and identification-based (Irmer and Druckman, 2009; Lewicki and Stevenson, 1997). And, identity has been treated as constituent-based representative role obligations (Druckman, 1994; Wall, 1975; Bartunek et al. 1975). Because of this emphasis on cognition, progress in 
developing theories or frameworks for understanding the role of emotions in negotiation has been slow. However, a spate of recent studies bodes well for development of this topic.

This chapter is organized by the perspectives that have guided the research to date on emotions in negotiation. Each perspective highlights a particular aspect of negotiation influenced by or influencing emotional expressions: namely, moves and exchanges (behavior), information processing (cognition), social interaction, and context. These perspectives capture several levels of analysis, including individual bargainers, dyads and groups, and the larger settings in which bargaining occurs. Taken together, the four perspectives cover much of what is known about emotions in and around the negotiation "table.” They also identify gaps in knowledge discussed in a final section as questions raised for further research.

\section{Behavioral Consequences of Emotions}

Most researchers explore the effects of specific emotions - typically anger and happiness - on observed behavior during the negotiation process. The first wave of this research compared how expressions of anger by a negotiator influence the other party's willingness to make concessions. Using programmed computer messages to convey anger to a negotiator, Van Kleef and his coworkers (van Kleef et al, 2004a) have consistently demonstrated that the strategic expression of anger elicits larger concessions from opponents. Consistent with the affect-as-information theories of emotion, the greater willingness to give concessions to angry opponents can be attributed to a negotiators' belief that angry negotiators have higher limits.

Subsequent research has focused on identifying the boundary conditions for this effect.

This research shows that anger is most effective at eliciting concessions when there is pressure to close the deal. This pressure may be interpersonal, when negotiators have a high need for cognitive closure, or contextual, when negotiators are bargaining under time pressure (Van Kleef 
et al, 2004b). These results suggest that anger may be most effective when negotiators are concerned about whether they will reach a deal, and diminish as the ease of reaching agreement increases. Consistent with this interpretation, Van Kleef et al. (2004 a) show that angry communications induce fear in negotiators. The link between expressed and anger and fear implies that, when negotiators express anger, they increase the other party's concerns about whether settlement is possible. Further support for this interpretation is provided by the finding that, in ultimatum bargaining games, negotiators make higher offers but also obtain poorer outcomes when the consequences of having their offers rejected are low (Nelissen, 2011; Van Dijk, 2008). While this relationship is mediated by fear and perceived threat (Nelissen, 2011; Sinaceur et al., 2011), it holds only when anger is expressed by a high power negotiator; when it is expressed by a low power negotiator, anger elicits reciprocal anger (Lelieveld, Van Dijk, Van Beest, \& Van Kleef, 2012)

The effectiveness of expressed anger is also affected by whether the anger is directed at the task or the other negotiators. Fisher and Ury (1981) exhort negotiators to focus on the problem, not the person. This maxim implies that emotions expressed in relation to the task will be more effective than emotions directed at the person. This reasoning holds in relation to anger. When negotiators express anger about the offer they have received they elicit more concessions than when they direct their anger at the other negotiator because they infer that the other party has high limits (Lelieveld et at., 2011; Steinel, 2008). Negotiators may opt to increase their own anger because they anticipate a difficult or confrontative negotiation. Doing so enables them elicit more concessions from their opponents (Tamir \& Ford, 2012). Interestingly, this effect is reversed when negotiators express either happiness or disappointment: both of these emotions, when directed at the person (rather then the offer) elicit more concessions from the 
other party (Lelieveld et at., 2011; Steinel, 2008). Finally, Harinck and Van Kleef (2012)

demonstrate that the benefits of anger are limited to conflicts about interests. When conflicts are about values, expressions of anger trigger retaliation and escalate conflict.

In a recent review, Van Kleef and his colleagues (2009) summarize the conditions that influence the interpersonal effects of anger. Anger is beneficial in producing favorable outcomes when: a. it is directed at the task rather than the person, b. it is viewed by the other as being justified, c. the relationship between bargainers is inter-dependent, d. the expression has informational value, e. the bargainers take a strategic approach that encourages using the expression as information that can aid coordination, and f. the target of anger has few opportunities to deceive. As noted above, strategic information may come from the other's verbal and non-verbal emotional expressions. Based on this summary of findings, the authors address the question: When does it pay to be angry? The answer is: When the parties are interdependent, when they use anger expressions strategically, and when the anger is seen as being justified.

A second, negative emotion that has received research attention is disappointment. Disappointment, as a discrete emotion, appears to shape the other party's offers because it triggers guilt in the other party (Lelieveld et at., 2011; Nelissen, 2011). This finding provides further support for this interpretation that, in repeat PDGs and ultimatum games and in divorce negotiations, guilt encourages higher levels of cooperation (Katelaar, 2003; Wietzker, Buysse, Loeys, \& Brondeel, 2012). Recent research identifies a boundary condition to this effect: when expressions of disappointment do not elicit guilt, for example when disappointment is expressed by out-group members, it leads to lower offers from counterparts (Lelieveld, Van Dijk, van Beest, \& Van Kleef, 2013). Similarly, in ultimatum games, feelings of regret result in more 
prosocial behavior (Martinez et al., 2011). And, mirroring the effect when negotiators are the targets of disappointment, individuals who feel disappointed decrease their prosocial behaviors (Martinez et al., 2011). Taken together, the research we have discussed so far suggests that to fully understand the impact of emotions in negotiations, not only do we need to differentiate between emotions with a similar valence but we also need to consider whether negotiators are the targets of expressed emotion or are experiencing the emotion themselves.

So far, we have focused on the impact of emotional expressions on obtaining increased concessions from an opponent. This research informs us about the ways in which expressing anger and other options might affect value claiming, but tells us less about how emotional expressions affect value creation. Nonetheless, an opponent's emotions are likely to provide indirect information about the relative priorities that she has assigned to specific issues. Focusing on the relationship between value creating (integrative) behaviors and emotions, Pietroni et al (2008) show that when negotiators display happiness in relation to high priority issues and anger in relation to low priority issues, value creating behaviors increase. However, when they display the reverse pattern (anger on high priority issues, happiness on low priority issues), integrative behaviors decrease. Moreoever, Kalokerinos, Greenway, Pedder and Margetts (2013) showed that negotiators who suppress happiness at winning are rated more positively and seen as more desirable friends, in part because the suppression of happiness conveys a desire to protect a counterpart's feelings.

This finding brings us to the role of positive emotions in negotiation. Negotiation researchers have, in recent years, paid considerably less attention to the consequences of positive emotions than to the consequences of negative emotions. Positive emotions, however, facilitate deal-making: Not only do they increase the likelihood that negotiators will reach a deal, but they 
also increase the likelihood that negotiators will be willing to deal with each other again in the future (Kopelman, Rosette, Thompson, 2006). Expressions of positive affect in employment negotiations result in greater willingness to implement the final agreement (Mislin, Campagna \& Bottom, 2011). These findings suggest that positive emotions may help negotiators to adopt a future-focus, facilitating agreements and strengthening ongoing relationships. These findings provide a tantalizing link to temporal construal theory, which suggests that distant time horizons are more likely to trigger cooperation and creativity than proximal time horizons (Henderson, Trope \& Carnevale, 2006; Trope; 2010). They raise the possibility that the different consequences of negative and positive emotions may be underpinned by a shift in negotiators' temporal horizons. This shift in temporal perspective is also recognized in studies of international negotiations. The distinction between backward and forward-looking outcomes distinguishes between proximal pasts and distant futures. Forward-looking outcomes result from more cooperative (and creative) negotiation processes (Zartman and Kremenyuk, 2005; Donohue and Druckman, 2009). The question of concomitant emotions raised to be studied in these contexts.

Linking emotion to decision frame, Carnevale (2009) tests the proposition that positive affect may shift negotiators' reference points and reverse the well-known framing effect. His research shows that happy negotiators are more cooperative. They make more concessions and more integrative offers to the other party. Importantly, he also demonstrates that the framing effect can be reversed under positive affect: Whereas affect-neutral negotiators were more resistant to making concessions under a loss frame, positive-affect negotiators were more resistant to making concessions under a gain frame. Carnevale’s findings raise several interesting questions for future research. The first is the link between affect and corresponding nonverbal 
behavior, the activation of neural systems and negotiators' behavior. Although this link between cooperative/competitive strategic choices and neural activity has been explored in the context of Prisoner's Dilemma Games, we are yet to understand how affective and neural systems shape strategic choices in the more ambiguous and uncertain context of negotiation. A start along these lines is made by the Druckman, Karis, and Donchin (1986) study of the relationship between the P300 EEG waveform, nonverbal behavior, and surprise in a bargaining task. Carnevale also highlights the importance of emotion-as-information, the idea that negotiators use their own affective states to guide their behavior.

\section{Cognitive Perspectives}

This perspective focuses on the relationship between emotions and information processing (e.g., Clore, Gasper and Garvan, 2001). Information search during bargaining depends for its effectiveness on skilled problem solving and judgments of authenticity. The former is a vigorous cognitive activity that contributes to better, more integrative outcome (Kressel et al., 1994). The latter involves interpretation about the other's intentions, which have been shown to be influenced by emotional expressions (Baron, 1990). Both skills, known as decoding (diagnosing the other's intentions) and encoding (conveying impressions), improve with practice (Thompson, 1990).

The need to interpret and respond to the other negotiator's intentions suggests that the strategic bargainer may be a Bayesian. This can be illustrated with anger. First, she ascertains whether the anger (or other expressions) being conveyed has informational value. Then she asks how often such outbursts have occurred in the past (a priori probabilities). The next step consists of updating. She may ask about whether the expression is justified, whether it is intended to communicate information about the other's limits, whether it is intended to convey information 
about the importance of the issue being discussed, or whether it indicates an impatience with the process or with herself, the target of the outburst. Each of these questions suggests a symptom that can be estimated in terms of probabilities. They are the contingent probabilities that contribute to a decision about reciprocating the anger (escalation) or mollifying the other (deescalation): The former is a likely reaction to unjustified anger; the latter to justified anger. The bargainer's choice influences the chances that the process will move in the direction of an impasse or an agreement.

These judgments may be formed against a background of greater or lesser certainty: Tiedens and Linton (2001) differentiate emotions associated with certainty, such as happiness and anger, from those associated with uncertainty, such as surprise, hope and fear. This distinction is based on whether, based on their experienced emotions, individuals are confident that they can (certain) or cannot (uncertain) predict what will happen next. A possible consequence is that predictions negotiators make about the other party are influenced not only by the valence of an emotion but also by the degree of certainty associated with that emotion. For example, happiness - a certain, positive emotion - will create strong optimistic expectations that the other party is skilled, that a settlement is likely and that cooperation is an appropriate strategy (e.g., Forgas, 1998). Conversely, anger - a certain, negative emotion - creates the expectation of a difficult, competitive negotiation, resulting in disinterest and withdrawal (Forgas, 1998; Knapp and Miller, 1985; Van Kleef, De Dreu and Manstead, 2004). This greater certainty is likely to result in greater confidence about what the other party will do next and decrease negotiators' responsiveness to the other's actual strategies. We know less about how uncertain emotions influence negotiation, but conclude that as the certainty associated with a specific negotiation decreases, negotiators are less confident about what the other party will do. This 
may result, on the one hand, in increased responsiveness and strategic flexibility but may, on the other hand, also increase vigilance and scrutiny of the other party's behaviors as negotiators strive to gain greater insight into their opponent's intentions.

Emotions are conveyed not only through speech, but also through nonverbal behaviors. Starting with Darwin's (1872) account of the processes of emotional expression in animals and humans, investigators have searched for the way in which different emotions are conveyed through speech and nonverbal behavior, particularly facial expressions. Woodworth's (1938) listing of primary emotions was the basis for studies designed to isolate expressions corresponding to each state (see Ekman and Friesen, 1975). These emotions are: happiness, surprise, fear, sadness, anger, disgust/contempt, and interest. A question asked in many of these studies is whether these are universal emotions or cultural-specific states (Ekman, 1972). For negotiation researchers, an important question concerns the connection between emotions and intentions.

Research on nonverbal indicators of deception has explored this connection (Ekman and Friesen, 1974; De Paulo et al., 1980). Honest and deceptive intentions have been shown to be associated with such emotional states as confidence, stress, and interest (Druckman, Rozelle, and Baxter, 1982). Each of these states has been found to be indicated by particular facial (and other bodily) expressions. For example, deceivers indicate confidence in defending positions through increased head shaking, rocking movements, and crossed hands; an attempt to evade an issue is accompanied by feelings of stress and indicated by frequent gazes away from the other person; an intention to be honest is accompanied by feelings of interest or involvement and indicated by frequent leg movements and increased speaking frequency. These correlational findings point to a connection between emotional states and particular intentions. They also highlight the 
possibilities for diagnosis (decoding) and impression management (encoding) in negotiation and related types of social exchange. Connections between the emotional expression of both negative and positive emotions and opportunities to deceive in negotiation are made in several recent studies (e.g., O’Connor and Canevale, 1997; Olekalns and Smith, 2007; Steinel and De Dreu, 2004).

More broadly, neuroimaging research suggests that emotions and cognitions are not distinct. These processes do not differ in kind. Rather, they interact in producing decisions. Both are influenced by interactive brain regions involved in basic psychological operations (Lindquist et al., 2012). With regard to negotiation, this means that intentional tactics, which may include evading or deceiving, combine elements of thought and feeling in an integrative rather than a sequential, competing, or additive fashion.

\section{Social Interaction Perspectives on Emotion}

Emotional expression also serves important social functions and assists in the coordination of social action. For individuals, emotions facilitate survival; for groups, they facilitate social bonding and collaboration (Keltner, Haidt, and Shiota, 2006; Shiota, Campos, Keltner and Hartenstein, 2004; Morris and Keltner, 2000). Emotions influence interaction processes when negotiators regard their expression as social information. Van Kleef (2009) develops this idea in the form of a model referred to as the emotions as social information (EASI) model. Drawing on research from a variety of areas, he demonstrates that expressions influence observers' behavior by triggering inferential processes and/or affective reactions in them. He regards inferences and affective reactions as different processes that vary in relative predictive strength depending on both the observer's information processing - for 
example, expressing sadness to solicit help or happiness to encourage volunteers to contribute to a cause -- and on such social-relational factors as the type of interpersonal relationship, prevailing norms, and the way the emotion is expressed (directed toward the person or the situation). Emotional expression is thus likely to play a role in the development of relationships between bargainers. Improved relationships have been shown to result from cooperative processes and mutually-beneficial outcomes (e.g., Druckman, 1998; Olekalns \& Smith, 2005). Importantly, the expression of positive emotion is identified as critical to forming and maintaining social bonds (Shiota et al., 2004).

This perspective suggests that emotions will influence not just a negotiator's behaviors and economic outcomes, but also social outcomes such as reputation and the ongoing relationship. One aspect of the social impact of emotions is the trust or mistrust that may develop between negotiators. The emotion-trust link, addressed by a small number of researchers, shows that the expression of positive emotions build trust among negotiators, suggesting that it is critical to problem-solving (Dunn \& Schweitzer, 2005). Refining our understanding of this relationship, Liu (2010) shows that whereas expressions of compassion are linked to trust, expressions of anger are linked to distrust. Conversely, Srivastava (2009) demonstrates a link between negative emotions, perceived unfairness and the willingness to retaliate in experimental games. A further consideration is whether expressed emotions (specifically anger) are judged to be authentic or strategic: strategically expressed anger reduces trust and elicits higher demands from opponents whereas authentic emotion increases perceived toughness and elicits lower demands from opponents (Cote, Hideg, and Van Kleef, 2013). Taking a slightly different direction, Kim, Cundiff and Choi (2014) show that negotiators' emotional intelligence is linked to their counterparts' trust in the negotiator, as well as their 
willingness to engage in future negotiations. An open question is whether emotional expression mediates the trust-outcome relationship or whether trust and emotions provide two distinct paths to shaping negotiators' outcomes. The interlocking relationships between trust and emotions may increase importance when, as we discuss in the next section, negotiations are among three or more parties.

Another approach, bridging the social interaction and cognitive perspectives, is provided by Goffman’s (1969) analysis of strategic interactions. Referred to as an expression game, he focuses on interactive dynamics between the roles of subject (making an offer or demand) and observer (receiving an offer or demand). This idea is a departure from the way research on negotiation (and on emotions) has been done. These roles are separated in much of the research: The focus of analysis is usually on the person receiving information from another or on the person sending information to another as in buyer-seller concession making. Less attention is paid to the interaction process where observer-subject interactions consist of alternating moves, the one attempting to infer intent from the subject's expressions, while the other attempts to convey certain expressions. In this process, each person is in easy reach of both the observer and subject roles. Reversed roles are a feature of the interaction that occurs as a result of mutual attempts to influence the other; the participant's sense of being more the subject or more the observer depends on whether he or she is persuading or analyzing during a particular episode in the process (see also Argyle et al., 1968; Pruitt, 1995). Interchangeable roles require that bargainers use both skills in the course of negotiation. And, both skills are essential for conveying and reading verbal and nonverbal emotional expressions in negotiation. Whether improved sensitivity to the meaning of expressions increases tactical proficiency in conveying intentions remains a research issue. 
This approach assumes that the dyad or group is the unit of analysis. This assumption departs from a good deal of the laboratory research where half the interaction is controlled by the experimenter: Messages are often sent from computers or confederates. Field research shows that, in the field, anger and other emotions may play out differently than in laboratory settings. For example, negotiators' outcomes are influenced not just by the valence of expressed emotions but also the linguistic patterns that evolve over time. In two studies of e-disputes, researchers showed that expressions of anger halved the likelihood of settlement and that the reciprocation of anger predicted a failure to resolve the dispute (Brett et al., 2007; Friedman et al, 2005). Positive emotions, on the other hand, had no impact on the likelihood of reaching settlement in a buyerseller dispute. However, Olekalns, Brett and Donohue (2010) show that, in child-custody disputes, the expression of positive emotions by wives, as well as the extent to which husbands 'caught' these emotions, shaped outcomes. Agreement was reached when husbands converged to wives high levels of positive emotion whereas impasses occurred when husbands converged to wives low levels of positive emotion. Similarly, hostage negotiations are more likely to conclude successfully when negotiators and hostage-takers reciprocate positive affect (Taylor, 2008). Jointly, these findings suggest that positive and negative emotions may not mark two ends of an emotional continuum. They also suggest that the domain in which negotiations occurs is linked to the relative efficacy of expressing positive or negative emotions.

Finally, negotiators' may 'catch' the emotion of the other party. Emotional contagion describes a phenomenon in which individuals experience others' emotion because of a general tendency to mimic and synchronize emotion (Barsade, 2002; Hatfield, Cacippo \& Rapson. 1993). Early experiments by Carnevale and Isen (1986) and by Johnson (1971a and b) demonstrated impacts of socially induced affect on negotiation. The former showed that when 
positive affect was induced, few contentious tactics were used and joint benefits were improved. The latter studies showed that scripted communications of warmth increased the other's liking but did not result in improved outcomes compared to a "cold" (angry) script. The most effective strategy was alternating between negative (acting cold) and positive (acting warm) emotions: Negotiators compromised more and evinced a larger change in attitudes when faced with an opponent who alternated between showing anger or warmth than when faced with opponents who were consistently angry or warm throughout the interactions. This finding suggests that there may be an advantage to "fine-tuning" one's expressions. The direction of negative and positive expressions may also be important. Concession-making studies showed that creating expectations for toughness early and a willingness to compromise later in the process lead to better outcomes.

These effects may be due to increased trust. Consistent with findings that emotional contagion increases group cohesion and rapport (Sy, Cote \& Saavedra, 2005), Swaab, Maddux, and Sinaceur (in press) showed that trust mediated the relationship between mimicking the other negotiator's language and outcomes: Linguistic mimicry during the early phases of the negotiation produced better outcomes for the mimicker. In an earlier study, Swaab and Swaab (2008) found that eye contact led to higher quality agreements for females but not for males: The visual contact increased comfort for the female negotiators but increased discomfort for the males. Together, these studies suggest that behaviors that increase either perceptions of trust or feelings of comfort lead to better outcomes. The findings also provide a bridge between the cognitive and social interaction perspectives. Verbal and nonverbal behaviors have diagnostic value for the strategic negotiator. They are used to infer intentions that either facilitate or impede interactions with consequences for outcomes. Negotiators should thus be able to strategically 
induce emotions in others, (potentially enhancing their outcomes) through the expression of emotion. For a review of the more general literature on socially induced affect, see Druckman and Bjork, 1994, chapter 10.)

\section{Contextual Influences on Emotion}

Missing as well from many laboratory studies is the way that emotional expressions are shaped by the contexts in which they are displayed. A contextualized view of emotions would complement the process view preferred by many negotiation researchers. Consequently, a key contribution of Van Kleef's EASI Model is to provide a framework for research on the interpersonal effects of emotions, thus also providing a link between the cognitive and social interaction perspectives on emotion. By including such moderating variables as power, time pressure, and display rules into the model, Van Kleef also incorporates contextual variables into the framework. Support for the model comes from studies on conflict and negotiation (e.g., Van Kleef , De Dreu, and Manstead, 2006). Further, the meta-analytic review conducted by Lindquist et al. (2012) shows that brain states evoked by emotional expressions are sensitive to context. Different brain states occur when the same emotion is elicited under different circumstances. This is illustrated by their example of fear and anger: the corresponding brain state depends upon labeling as fear or anger and the social setting as a physical or social context.

Power, frequently a very salient contextual variable in negotiations, provides an important lens through which to view expressions of anger. Social cognition research suggests that, because they process information systematically and are more attuned to the social consequences of their actions, low power negotiators are likely to be more responsive to emotion displays than high power negotiators. Consistent with these general findings, low power negotiators concede more to others who express anger and also claim less value from angry 
opponents (Butt \& Choi, 2009; Van Kleef et al., 2006; Van Kleef \& Cote, 2007; Sinaceur \& Tiedens, 2006). High power negotiators are also influenced by anger; however they respond both to their own and the other party's emotional state. Responding to their own anger, high power negotiators are energized: they report feeling more focused and assertive, claiming more value in the negotiation (Overbeck et al., 2010). In response to the other's anger, they increase their demands when they believe that anger is unjustified (Van Kleef \& Cote, 2007). Finally, powerful negotiators set the emotional tone for a negotiation: their positive affect underpins the level of trust in the negotiation (Anderson \& Thompson, 2004).

Research on e-communication sheds further light on the expression of emotion in negotiations and disputes. When negotiations occur electronically, they are more likely to be successful if negotiators express positive emotions and agreeableness. Critically, although expressions of agreeableness at any time during an e-negotiation facilitate settlement, negative emotions affect success only when they are expressed in the second half of the negotiation. These findings in the domain of negotiation parallel research in the domain of dispute resolution. Two studies investigating eBay disputes show that the expression of negative emotions and anger delay and may prevent settlement (Brett et al., 2007; Friedman et al., 2005). This line of research highlights the importance of emotional tone as well as timing. When emotions are expressed and the extent to which others then converge to those emotions contributes to their impact on the outcome.

Because the expression of emotions is socially determined, we might also expect that the impact of emotional expression varies across culture. For example, the emphasis on harmony and preserving face in Asian cultures suggests that these cultures might be more reluctant to express negative emotions. Following this line of thought, Adam, Shirako and Maddux (2010) 
show that expressions of anger elicit larger concessions for European American but smaller concessions from Asian and Asian American negotiators. Subsequent research shows that anger conveys greater toughness and threat when expressed by East Asians than when expressed by European Americans (Adam \& Shirako, 2013). Expressions of anger also affect what negotiators do next: Chinese negotiators are more likely than American negotiators to respond to anger by increasing their use of persuasive arguments (Liu, 2009). Further insight into the impact of culture-based norms is provided by Kopelman and Rosette (2009), who explore the issue of culture-specific relationships between accepting offers and accompanying emotional expressions. They show that Asian negotiators are more likely to accept ultimatum offers that are made in the context of positive emotions than those made in the context of negative emotions; however, Israeli negotiators are indifferent to whether an offer is accompanied by expressions of positive or negative emotions.

The same reasoning about norms of appropriateness can be applied to gender: like culture, gender might determined what is perceived as appropriate emotional expression and consequently affect the impact of those emotions. In general, women are expected to both experience and express a greater range of emotions than men. The two exceptions to this general expectation relate to expressions of anger and pride, both of which are seen as more typical of men than women. (Plant, Hyde, Keltner and Devine, 2000). Consistent with this view, men who express anger are more likely to obtain positive organizational outcomes than women who express anger (Gibson et al., 2009). The idea that there are gender- and culture-based expectations about emotional expression is interesting, in light of work on expectancy violation and emotion in negotiation: Negotiators who switch strategies and thereby violate the 
expectations of the other negotiator influence that party's mood (Barry and Oliver, 1996;

Olekalns, Roberts, Probst, Smith and Carnevale, 2005).

A broader context of interest, also associated with regulatory norms, is the organization. Directions for research on emotions in organizations is made by Fineman and his contributors. He asks: "In what ways do decisions unfold over time as a function of the way people feel, and change their feelings - about themselves, their projects and significant others? How, for example does anxiety, suspicion, love, and hate take decision making through various paths towards particular outcomes?” (1993: 217). These questions are also at the heart of research on negotiation. Stretching back to Walton and McKersie’s (1965) intra-organizational model of labor negotiation, researchers have explored the way that negotiation occurs within and between organizations - particularly with regard to boundary roles (Adams, 1976; Burke and Biggert, 1997). The research has, however, been more concerned with strategies than with emotional expressions.

Context also changes when individuals move from dyadic to multi-party negotiations. As is the case in dyadic negotiations, expressions of anger and negative emotions decrease agreement. More importantly, negotiators who express anger are likely to be excluded from coalitions and hence lose their share of the outcome (Huffaker, 2011; Van Beest, 2008). However, if negotiators are forced or choose to form an alliance with an angry player then, as is the case in dyadic negotiations, angry negotiators obtain large concessions. Recently, van Beest and Scheepers (2013) refined our understanding of the role played by anger in coalition formation: negotiators who receive an angry message from a preferred coalition partner show a cardiovascular response consistent with challenge, whereas those who received an angry message from non-preferred coalition partner that show a cardiovascular response consistent 
with threat. An interesting consequence is that challenged, but not threatened, negotiators are more likely to find a new coalition partner.

The flip side is that building perceived similarity, through linguistic convergence, increases agreement between coalition partners (Huffaker, 2011). When integrated with the positive emotion-trust link we described earlier, these findings suggest that positive emotions might strengthen alliances and enable negotiators to improve their outcomes (also, Olekalns, Lau \& Smith, 2007). Our understanding of the role of emotion in multi-party negotiations is in its infancy. However, the possibility that emotional expression shapes coalition formation and agreement suggests that we need better understanding of the role that emotional expressions play in multi-party negotiations.

Finally, recent research has investigated the longer-term consequences of emotional expression. In their study, Van Kleef and De Dreu (2011) tested the long-term consequences of expressing anger in a negotiation. They contrasted a spillover model, which suggests that the target of anger would demand less in a subsequent negotiation, with a retaliation model, which suggests that a target would demand more in a subsequent negotiation. They found support for the spillover model: negotiators demanded less when they had a second negotiation with the same angry negotiators because they perceived that negotiator to be tough. Taking the idea of timing in a slightly different direction, Filipowicz et al. (2011) compared the impact of consistently expressed emotions throughout a negotiation to the impact of emotional transitions. They found that, compared to negotiators who are consistent in their emotional expressions, negotiators who 'become angry' obtain better outcomes and also conveyed a more positive impression than negotiators who 'become happy’. Similarly, Sinacuer, Adam, Van Kleef, and 
Galinsky (2013) report that emotional inconsistency elicits greater concessions than emotional consistency.

\section{New Directions for Research}

To date, negotiation researchers have focused on a relatively narrow range of behaviors. Moreover, despite complex models of emotion in other domains, negotiators have neither connected with these literatures nor sampled systematically across different dimensions of emotion. Negotiation researchers continue to concentrate their work primarily on two emotions, happiness and anger. A few studies have examined impacts of surprise on bargaining moves (e.g., Druckman, Karis, and Donchin, 1986) and on the arousal of guilt when outcomes clearly favor oneself (Hegtvedt and Killian, 1999). These and other emotional states have been studied in psychology more generally. One well-known model, the circumplex model of affect (Russell,1980), differentiates emotions based on their valence (positive or negative) as well as their arousal level (active vs. passive). We encourage negotiation researchers to more systematically assess how emotions around the affect circumplex affect negotiators' behaviors and outcomes.

More recent research also shows strong links between emotions and the activation different regions of the brain. The effects of mimicking have been shown to be associated with mirror neurons, which fire either when an individual acts or observes an action underlie the effects of mimicry that we described earlier (van der Gaad, Minderaa, \& Keysers, 2007; Wicker, Keysers, Plailly, Royet, Gallese \& Rizzolatti, 2003). Similarly, emotions from different quadrants of the affect circumplex trigger activity in different regions of the brain: research shows that distinct brain regions activate depending on the valence and arousal of a specific 
emotion (Colibazzi et al., 2010; Posner et al., 2009). More recently, de Dreu and his coworkers have linked oxytocin to in-group trust and cooperation in the face of intergroup conflict (De Dreu et al., 2010). These findings, because they show that different brain regions are activated by different emotions, underscore the importance of sampling emotions around the affect circumplex because they imply that similarly valence emotions may evoke distinctly different reactions. They further underscore the need to better understand the neurophysiological factors that drive our emotional experiences and our reactions to others.

Related research examines the physiological aspects of negotiation. Two studies examining arousal show heightened arousal, which can be triggered by a fit negotiators agreeableness and the negotiating context, leads to better economic outcomes especially if negotiators feel positive about the negotiation, (Brown \& Curhan, 2013; Dimotakis, Conlon, Ilies, 2012). Returning to our discussion of mimicry, research shows that negotiators who suppress their own emotions are less sensitive to to facial expressions of emotion in their counterparts than negotiators who engage in mimcry (Schneider, Hempel, \& Lynch, 2013). This finding highlights a dilemma for negotiators who, on the one hand, may benefit from concealing their emotions yet, on the other hand, incur the costs of failing to recognize opponents' emotional reactions.

Many of the studies we reviewed were conducted in laboratories. An advantage of the laboratory controls is that the direction of influence -- from the computer/actor to the subject - is clear. Causal inferences can be made with confidence. A disadvantage is that interactive dynamics are ignored. The result is a loss in relevance to real-world negotiations. This trade off, favoring internal over external validity, is a feature of much of the research to date. A better balance between the two validities will materialize when researchers take on the challenge of 
field research. The interaction dynamics described by field researchers would complement the causal patterns inferred from the laboratory studies. Add to this the challenges of studying a phenomenon that is fleeting - as in changing moods during the course of an interaction - and vaguely defined - as when multiple meanings are inferred from expressions - and there is little wonder that the research to date has progressed slowly. Emotions are not easy to investigate. But, there is little doubt that it is important to study them.

Of particular interest are research questions that cross the four perspectives. Examples include the following: (a) How are concessions (behavioral perspective) influenced by attributions of the other negotiator's intentions (cognitive perspective)?; (b) How are interaction dynamics (social interaction perspective) shaped by the connection between decoding/interpretation and encoding/conveying expressions (cognitive perspective)?, To what extent does Van Kleef's EASI model contribute to understanding this connection? ; (c) Which emotional expressions -- and the corresponding link to negotiating behavior - are more or less influenced by such contextual variables as culture and gender?; and (d) What role do emotional expressions play in the development of long-term relationships between negotiators?, How is this connection - between emotions and social relationships - mediated by contextual variables?

\section{Conclusions}

The findings that we have discussed identify an interesting set of issues for continuing research within each perspective on emotions in negotiation. First, we can look forward to studies that examine other emotions such as surprise when expectations are disappointed, sadness when alternatives are unattractive and dependency increases, shame when face is lost, and interest or involvement when the stakes increase. Second, the interplay between emotions and cognitions present an interesting array of research challenges: for example, the way that 
bargainers use affective information to develop or change strategies. Third, process dynamics call for further investigation. In particular, interactive processes such as those described by the expression-game paradigm need to be better understood. A related issue is the coordination of emotional expressions: When does matching perpetuate impasses and when does it resolve them? Fourth, there is much yet to be learned about the contexts for emotional expression. Included in these contexts are the number of parties, organizational norms, and cultures. A question of interest is how these contexts shape the way emotions are expressed and read. The idea of cultural display rules may be relevant also for organizations and the institutional contexts within which negotiation occurs. 


\section{References}

Adam, H., \& A. Shirako. (2013). Not all anger is created equal: The impact of the expresser’s culture on the social effects of anger in negotiations. Journal of Applied Psychology, 98, 85798.

Adam, H., Shirako, A., and Maddux, W. (2010). Cultural variance in the interpersonal effects of anger in negotiations, Psychological Science, 21, 882-889.

Adams, J.S. (1976). The structure and dynamics of behavior in organizational boundary roles. Iin M.D. Dunnette (Ed.), Handbook of Industrial and Organizational Psychology. Chicago: Rand McNally.

Anderson, C., and Galinsky, A. (2006). Power, optimism and risk-taking,” European Journal of Social Psychology 36, 511-536.

Anderson, C., and L. Thompson (2004). Affect from the top down: How powerful individuals' positive affect shapes negotiations. Organizational Behavior and Human Decision Processes 95, 125-139.

Argyle, M., M. Lalljee, and M. Cook (1968). The effects of visibility on interaction in a dyad. Human Relations 21, 3-17.

Baron, R.A. (1990). Environmentally-induced positive affect: Its impact on self-efficacy, task performance, negotiation, and conflict. Journal of Applied Social Psychology 20, 368-384.

Barsade S.G. (2002). The Ripple Effect: Emotional Contagion and Its Influence on Group Behavior. Administrative Science Quarterly; 47, 644-675

Bartunek, J.M., A. Benton, and C.B. Keys (1975). Third party intervention and the bargaining behavior of group representatives. Journal of Conflict Resolution 19, 532-557. 
Brett, J., , Olekalns, M., Friedman, R., Goates, N., Anderson, C., and C. Lisco (2007).

Sticks and stones: Language and on-line dispute resolution. Academy of Management Journal 50, 85-99.

Brown, A. D. \& J.R. Curhan. (2013). The polarizing effect of arousal on negotiation. Psychological Science, 24, 1928-1935.

Burke, W. and N. Biggert (1997). Inter-organizational cooperation. In D. Druckman, J. Singer, and H. Van Cott (Eds.) Enhancing Organizational Performance. Washington DC: National Academy Press.

Butt, A.N. and J.N. Choi (2009). Does power matter? Negotiator status as a moderator of the relationship between negotiator emotion and behavior. International Journal of Conflict Management 21 (2), 124-146.

Carnevale (2008). Positive affect and decision frame in negotiation. Group Decision and Negotiation 17 (1), 51-63.

Carnevale, P. and A.M. Isen (1986). The influence of positive affect and visual access on the discovery of integrative solutions in bilateral negotiation. Organizational Behavior and Human Performance 37, 1-13.

Clore, G.L., K. Gasper, and E. Gavin (2001). Affect as information. In J.P. Forgas (Ed.), Handbook of Affect and Social Cognition. Mahwah, NJ: Lawrence Erlbaum Associates.

Côté, S., I. Hideg, and G.A. van Kleef (2013). The consequences of faking anger in negotiations. Journal of Experimental Social Psychology, 49, 453-463.

Daly, J.P. (1991). The effects of anger on negotiations over mergers and acquisitions. Negotiation Journal 7, 31-39.

Darwin, C. (1872). The Expression of the Emotions in Man and Animals. London: Murray. 
De Dreu, C.K.W., et al. (2010). The Neuropeptide Oxytocin Regulates Parochial Altruism in Intergroup Conflict Among Humans, Science, 328, 1408.

De Dreu, C.K.W., L. Weingart, and S. Kwon (2002). Influence of social motives on integrative negotiation: A meta-analytic review and test of two theories. Journal of Personality and Social Psychology 78, 889-905.

DePaulo, B.M., M. Zuckerman, and R. Rosenthal (1980). “Detecting deception: Modality effects. In L. Wheeler (Ed.), Review of Personality and Social Psychology, Vol. 1. Beverly Hills, CA: Sage.

Deutsch, M. (1985). Distributive Justice: A Social-Psychological Perspective. New Haven, CT: Yale University Press.

Dimotakis, N., D.E., Conlon, \& R. Ilies. (2012). The mind and heart (literally) of the negotiator: Personality and contextual determinants of experiential reactions and economic outcomes in negotiation. Journal of Applied Psychology, 97,183-193.

Donohue, W.A. and D. Druckman (2009). Message framing surrounding the Oslo I accords. Journal of Conflict Resolution 53 (1): 119-145.

Druckman, D. (1998). Social exchange theory: Promises and prospects. International Negotiation 3, 253-266.

Druckman, D. (1994). Determinants of compromising behavior in negotiation: A meta-analysis. Journal of Conflict Resolution 38, 507-556

Druckman, D. and R.A. Bjork (1994), Learning, Remembering, and Believing: Enhancing Human Performance. Washington DC: National Academy Press.

Druckman, D., D. Karis, and E. Donchin (1986). Information-processing in bargaining: 
Reactions to an opponent's shift in concession strategy. Iin R. Tietz (Ed.) Aspiration Levels in Bargaining and Economic Decision Making, Springer. Berlin- Heidelberg-New York.

Druckman, D., R. Rozelle, and J. Baxter (1982). Nonverbal Communication: Survey, Theory, and Research. Beverly Hills, CA: Sage.

Dunn, J.R., and M. E. Schweitzer (2005). Feeling and believing: The influence of emotion on trust. Journal of Personality and Social Psychology, 88, 736-748.

Ekman, P. (1972). Universal and cultural differences in facial expressions of emotion. Iin J.K. Cole (Ed.) Nebraska Symposium on Motivation. Lincoln, Nebraska: University of Nebraska Press.

Ekman, P. and W.V. Friesen (1975). Unmasking the Face: A Guide to Recognizing Emotions from Facial Clues. Englewood Cliffs, NJ: Prentice-Hall.

Ekman, P. and W.V. Friesen (1974). "Detecting deception from the body or face. Journal of Personality and Social Psychology 29, 288-298.

Filipowicz, A., S., Barsade, S., and S. Melwani. (2011). "Understanding emotional transitions: The interpersonal consequences of changing emotions in negotiations”, Journal of Personality and Social Psychology, 101, 541-556.

Forgas, J.P. (1998). “On feeling good and getting your way: Mood effects on negotiator cognition and bargaining strategies. Journal of Personality and Social Psychology, 74, 565577.

Fineman, S. (Ed.) (1993). Emotion in Organizations. London: Sage.

Friedman, R., J. Brett, C. Anderson, M. Olekalns, N. Goates, and C. Lisco (2004). Emotions and rationality in mediation: Evidence from electronically-mediated disputes. Journal of Applied Psychology, 89, 369-376. 
Gibson, D., M. Schweitzer, R. Callister, and B. Gray (2009). The influence of anger expressions on outcomes in organizations. Negotiation and Conflict Management Research, 2, 236-262.

Goffman, E. (1969). Strategic Interaction. Philadelphia: University of Pennsylvania Press. Harinck, F.and Van Kleef, G. A. (2012). Be hard on the interests and soft on the values: Conflict issue moderates the effects of anger in negotiations. British Journal of Social Psychology, 51: 741-752.

Hatfield, E., J.T., Cacioppo, and R.L. Rapson. (1993). Emotional contagion. Current Directions in Psychological Science, 2, 96-99.

Hegtvedt, K.A. and C. Killian (1999). Fairness and emotions: Reactions to the process and outcomes of negotiations. Social Forces 78, 269-303.

Henderson, M.D., Y., Trope, Y., and P.J. Carnevale. (2006). Negotiating from a near and distant time perspective, Journal of Personality and Social psychology, 4, 712-729.

Hine, M., Murphy, S.A.., Weber, M., and Kersten, G. (2009). The role of emotion and language in dyadic e-negotiations. Group Decision and Negotiation. 18, 193-211.

Hopmann, P.T. (1995). Two paradigms of negotiation: Bargaining and problem solving. Annals of the American Academy of Political and Social Science 542, 24-47.

Huffaker, D.A., R. Swaab, and D. Diermeier (2011). The language of coalition formation in online multiparty negotiations. Journal of Language and Social Psychology, 30, 66-81.

Irmer, C. and D. Druckman (2009). Explaining negotiation outcomes: Process or context? Negotiation and Conflict Management Research 2 (3): 209-235. 
Jehn, K.A. (1994). Enhancing effectiveness: An investigation of advantages and disadvantages of value-based intergroup conflict. International Journal of Conflict Management 5, 223238.

Johnson, D.W. (1971a). The effects of warmth of interaction, accuracy of understanding, and the proposal of compromises on the listener's behavior. Journal of Counseling Psychology 18, 207-216.

Johnson, D.W. (1971b). "Effects of the order of expressing warmth and anger on the actor and listener.” Journal of Counseling Psychology 18: 571-578.

Kalokerinos, E., K. Greenaway, D. Pedder and E. Margetts. (2013). Don’t grin when you win: the social costs of positive emotion expression in performance situations, Emotion, 14, 180186.

Ketelaar, T. and W.T. Au (2003). The effects of feelings of guilt on the behavior of uncooperative individuals in repeated social bargaining games: An affect-as-information interpretation of the role of emotion in social interaction, Cognition and Emotion, 17, 429453.

Keltner, D., J. Haidt, and M.N. Shiota (2006). Social functionalism and the evolution of emotions. In M. Schaller, J. A. Simpson, and D.T. Kenrick, (Eds.), Evolution and Social Psychology: Frontiers of Social Psychology, Madison, CT,: Psychosocial Press.

Kim, K., N. L. A. Cundiff, and S. B. Choi. (2014). The influence of emotional intelligence on negotiation outcomes and the mediating effect of rapport: A structural equation modeling approach. Negotiation Journal, 30, 49-68

Kopelman, S., \& A. Rosette (2008). Cultural variation in response to strategic emotions in negotiation. Group Decision and Negotiation 17: 65-77. 
Kopelman, S., Rosette, A., \& Thompson, L. (2006). The three faces of Eve: Strategic displays of positive, negative, and neutral emotions in negotiations, Organizational Behavior and Human Decision Processes, 99, 81-101

Kressel, K., E. Frontera, S. Forlenza, F. Butler, and L. Fish (1994). The settlement orientation vs. the problem-solving style in custody mediation. Journal of Social Issues 50, 67-84.

Lelieveld, Gert-Jan; Van Dijk, Eric; Van Beest, Ilja; Van Kleef, Gerben A. (2013). Does communicating disappointment in negotiations help or hurt? Solving an apparent inconsistency in the social-functional approach to emotions, Journal of Personality and Social Psychology, 105, 605-620.

Lelieveld, G., Van Dijk, E., Van Beest, I., Steinel, W., and Van Kleef, G. (2011). Disappointed in you, angry about your offer: Distinct negative emotions induce concessions via different mechanisms. Journal of Experimental Social Psychology, 47, 635-641.

Lelieveld, Gert-Jan; Van Dijk, Eric; Van Beest, Ilja; Van Kleef, Gerben A. (2012). Why anger and disappointment affect other's bargaining behavior differently: The moderating role of power and the mediating role of reciprocal and complementary emotions. Personality and Social Psychology Bulletin, 38, 1209-1221.

Lindquist, K.A. et al. (2012), The brain basis of emotion : A meta-analytic review. Behavioral and Brain Sciences 35, 121-202.

Liu, M., and Wang, C. (2010). Explaining the influence of anger and compassion on negotiators' Interaction goals: An assessment of trust and distrust as two distinct mediators. Communication Research, 37, 443-472.

Liu, M. (2009). The intrapersonal and interpersonal effects of anger on negotiation strategies: A cross-cultural investigation. Human Communication Research, 35 , 148-169. 
Lewicki, R. and Stevenson, M. (1997). Trust development in negotiation: Proposed actions and a research agenda. Paper presented at the conference on Trust and Business: Barriers and Bridges, DePaul University, Chicago.

McIntosh, D.N. (1996). Facial feedback hypotheses: Evidence, implications, and directions. Motivation and Emotion 20, 121-147.

Mislin, A., Campagna, R.L., \& Bottom, W.P. (2011). After the deal: Talk, trust building and the implementation of negotiated agreements, Organizational Behavior and Human Decision Processes, 115, 55-68.

Morris, M.W., and Keltner, D. (2000). How emotions work: The social functions of emotional expression in negotiations. Research in Organizational Behavior 22, 1-50.

Nelissen , R.A., M. Leliveld, E. van Dijk, and M. Zeelenberg (2011). Fear and guilt in proposers: Using emotions to explain offers in ultimatum bargaining. European Journal of Social Psychology 41, 78-85.

O’Connor, K., and P. Carnevale (1997). A nasty but effective negotiation strategy: Misrepresentation of a common-value issue. Personality \& Social Psychology Bulletin 23, 504-519.

Olekalns, M., Brett., J., \& Donohue, W. (2010). Words Are All I Have: Linguistic Cues as Predictors of Settlement in Divorce Mediation, Negotiation and Conflict Management Research, 3, 145-168.

Olekalns, M., and P. Smith (2007). Willing and able? Trust, affect and power balance as predictors of deception in negotiation. Melbourne Business School Working Paper 2007-08.

Olekalns, M., and P. Smith (2005). Moments in time: Metacognition, trust and outcomes in negotiation. Personality \& Social Psychology Bulletin 31, 1696 - 1707. 
Overbeck, J.R., M.A. Neale, and C.L. Govan (2010). I feel, therefore you act: Intrapersonal and interpersonal effects of emotion on negotiation as a function of social power. Organizational Behavior and Human Decision Processes 112, 126-139

Pearson, T. (1990). The Role of Symbolic Gestures in Intergroup Conflict Resolution: Addressing Group Identity. Unpublished doctoral dissertation, Harvard University, Cambridge, MA.

Pietroni, D., G. Van Kleef, C. De Dreu, and S. Pagliaro (2008). Emotions as strategic information: Effects of other's emotional expressions on fixed-pie perception, demands, and integrative behavior in negotiation, Journal of Experimental Social Psychology 44, 14441454.

Plant, E.A., J. S. Hyde, D. Keltner, and P. G. Devine (2000). The gender stereotyping of emotions._Psychology of Women Quarterly 24, 81-92.

Pruitt, D.G. (1995). Flexibility in conflict episodes. Annals of the American Academy of Political and Social Science 542, 100-115.

Rudman, L., and P. Glick (1999). Feminized management and backlash toward agentic women: The hidden costs to women of a kinder, gentler image of middle managers. Journal of Personality and Social Psychology 77, 1004-1010.

Russell, J.A. (1980). A circumplex model of affect, Journal of Personality and Social Psychology, 39, 1161-1178.

Schneider, K., R. Hempel and T. Lynch. (2013.) That “Poker” just might lose you the game! The impact of expressive suppression and mimicry on sensitivity to facial expressions of emotion. Emotion 13(5): 852-8666. 
Shiota, M.N., D. Keltner, and M. J. Hertenstein (2004). Positive emotion and the regulation of interpersonal relationships. In P. Philippot and R.S. Feldman, (Eds.), The Regulation of Emotion. Hillsdale NJ: Lawrence Erlbaum Associates.

Sinaceur, M., and L. Tiedens (2006). Get mad and get more than even: When and why anger expression is effective in negotiations. Journal of Experimental Social Psychology 42, 314322

Sinaceur, M, H. Adam, G.A. Van Kleef, and A.D. Galinsky (2013). The advantages of being unpredictable: How emotional inconsistency extracts concessions in negotiation. Journal of Experimental Social Psychology, 49, 498-508

Sinaceur, M., G. A. Van Kleef, M. Neale, H. Adam, and C. Haag (2011). Hot or cold: Is communicating anger or threats more effective in negotiation? Journal of Applied Psychology 96, 1018-1032

Srivastava, J., F. Espinoza, and A. Fedorikhin (2009). Coupling and decoupling of unfairness and anger in ultimatum bargaining. Journal of Behavioral Decision Making 22, 475-489.

Steinel, W., G.A. Van Kleef, and F. Harinck (2008). Are you talking to me?! Separating the people from the problem when expressing emotions in negotiation. Journal of Experimental Social Psychology 44, 362-369.

Steinel, W., and C.K.W. De Dreu (2004). Social motives and strategic misrepresentation in social decision making. Journal of Personality and Social Psychology 86, 419-434.

Swaab, R.I. and D,F. Swaab (2008). Sex differences in the effects of visual contact and eye contact in negotiations. Journal of Experimental Social Psychology 45: 129-136. 
Swaab, R.I., W.W. Maddux, and M. Sinaceur (in press). Early words that work: When and how linguistic mimicry facilitates negotiation outcomes. Journal of Experimental Social Psychology.

Sy T., Cote S., \& Saavedra R. (2005). The Contagious Leader: Impact of the Leader’s Mood on the Mood of Group Members, Group Affective Tone, and Group Processes. Journal of Applied Psychology, 90, 295-305.

Tamir, M., \& B.Q. Ford. (2012). When feeling bad is expected to be good: Emotion regulation and outcome expectancies in social conflicts. Emotion, 12, 807-816.

Taylor, P. and S. Thomas (2008). Linguistic style matching and negotiation outcome. Negotiation and Conflict Management Research 1, 263-281.

Thompson, L. (1990). An examination of naïve and experienced negotiators. Journal of Personality and Social Psychology 59, 82-90.

Tiedens, L.Z., and S. Linton (2001). Judgment under emotional certainty and uncertainty: The effects of specific emotions on information processing. Journal of Personality and Social Psychology 81, 973-988.

Trope, Y., \& Liberman, N. (2010). Construal-Level Theory of Psychological Distance, Psychological Review, 117, 440-463.

van Beest, I., \& D. Scheepers. (2013). Challenge and threat responses to anger communication in coalition formation. Journal of Economic Psychology, 38, 50-57.

van Beest, I., G. A. Van Kleef, and E. Van Dijk, E. (2008). Get angry, get out: The interpersonal effects of anger communication in multiparty negotiation. Journal of Experimental Social Psychology 44, 993-1002.

Van Dijk, E., G.A. Van Kleef, W. Steinel, and I.van Beest (2008). A social functional 
approach to emotions in bargaining: When communicating anger pays and when it backfires. Journal of Personality and Social Psychology 94, 600-614.

van der Gaad, C., Minderaa, R.B., \& Keysers, C. (2007). Facial expressions: What the mirror neuron system can and cannot tell us. Social Neuroscience, 2, 179-222.

Van Kleef (2009). How emotions regulate social life: The emotions as social information (EASI) model. Current Directions in Psychological Science 18 (3): 184-188.

Van Kleef, G., and S. Cote (2007). Expressing anger in conflict: When it helps and when it hurts, Journal of Applied Psychology 92, 1557-1569

Van Kleef, G.A. and C. De Dreu, C.K.W. (2010). Longer-term consequences of anger expression in negotiation: Retaliation or spillover? Journal of Experimental Social Psychology. 46, 753-760.

Van Kleef, G.A. and P.A.M.Van Lange (2008). What other's disappointment may do to selfish people: Emotion and social value orientation in a negotiation context. Personality and Social Psychology Bulletin 34, 1084-1095.

Van Kleef, G.A., C.K.W. De Dreu, and A.S.R. Manstead (2006). Supplication and appeasement in conflict and negotiation: The interpersonal effects of disappointment, worry, guilt, and regret. Journal of Personality and Social Psychology 91: 124-142.

Van Kleef, G.A, C.K.W. De Dreu, D. Pietroni, and A.S. Manstead (2006). Power and emotion in negotiation: Power moderates the interpersonal effects of anger and happiness on concession making. European Journal of Social Psychology 36, 557-581.

Van Kleef, G.A, C.K.W. De Dreu, and A.S. Manstead (2004). The interpersonal effects of anger and happiness in negotiations. Journal of Personality and Social Psychology 86, 5776. 
Wall, J.A. (1975). Effects of constituent trust and representative bargaining orientation in intergroup bargaining. Journal of Personality and Social Psychology 31, 1004-1112.

Walton, R.E. and R.B. McKersie (1965). A Behavioral Theory of Labor Negotiations: An Analysis of a Social Interaction System. New York: McGraw-Hill.

Wicker, B., Keysers, C., Plailly, J., Royet, J.P., Gallese, V., \& Rizzolatti, G. (2003). Both of us disgusted in my insula: the common neural basis of seeing and feeling disgust. Neuron, 40, 655-664.

Wietzker, A., A. Buysse, T. Loeys, Tom, and R. Brondeel (2012) Easing the conscience: Feeling guilty makes people cooperate in divorce negotiations. Journal of Social and Personal Relationships 29: 324-336.

Woodworth, R.S. (1938). Experimental Psychology. New York: Henry Holt.

Zartman, I.W. and V. Kremenyuk (2005). Peace versus Justice: Negotiating Forward- and Backward-Looking Outcomes. Lanham MD: Rowman \& Littlefield Publishers. 


\section{University Library}

\section{- M M I N E R VA A gateway to Melbourne's research publications}

Minerva Access is the Institutional Repository of The University of Melbourne

Author/s:

OLEKALNS, M

Title:

With Feeling: How Emotions Shape Negotiation

Date:

2015

Citation:

OLEKALNS, M. (2015). With Feeling: How Emotions Shape Negotiation. Martinovsky, B (Ed.). Emotion in Group Decision and Negotiation, Emotion in Group Decision and Negotiation, (1), 7, pp.33-50. Springer.

Persistent Link:

http://hdl.handle.net/11343/118402 